\title{
AVALIAÇÃO DAS CONDIÇÕES CONSTRUTIVAS E DA QUALIDADE DE ÁGUA DO PROGRAMA UM MILHÃO DE CISTERNAS NA COMUNIDADE RURAL DE POÇOS EM CAJAZEIRAS-PB
}

\author{
EVALUATION OF CONSTRUCTIVE CONDITIONS AND THE WATER \\ QUALITY OF THE PROGRAM UM MILHÃO DE CISTERNAS IN THE \\ RURAL COMMUNITY OF POÇOS IN CAJAZEIRAS-PB
}

\author{
Dauany Kalyne Lourenço ${ }^{1}$ \\ Rafael Wandson Rocha Sena ${ }^{2}$ \\ Thalita Maria Ramos Porto ${ }^{3}$ \\ Guilherme Urquisa Leite ${ }^{4}$ \\ Hellykan Berliet dos Santos Monteiro ${ }^{5}$ \\ Maria Aparecida Bezerra Oliveira ${ }^{6}$
}

\footnotetext{
${ }^{1}$ Graduanda em Engenharia Civil pela Faculdade Santa Maria - FSM.

${ }^{2}$ Graduado em Engenharia Civil pela Universidade Estadual Vale do Acaraú (2012); Mestre em Engenharia Civil em Estruturas pela Universidade Federal do Ceará (2015). Especialista em Docência no Ensino Superior (2017). Atualmente professor do curso de Engenharia Civil na Faculdade Santa Maria (Cajazeiras-PB).

${ }^{3}$ Engenheira civil (2015), formada pela Universidade federal de Campina Grande- UFCG. Atuei como engenheira júnior no ano de 2016 na Construtora Norte Nordeste ME Ltda, realizando fiscalização e gerenciamento de obras. Mestre (2018) em Engenharia Civil e Ambiental (PPGECA? UFCG) e Doutoranda em Engenharia Civil e Ambiental pela UFCG. Sou professora desde 2016, lecionei em instituições de ensino técnico como Grau Técnico e Infogenius, responsável por disciplinas nas áreas da construção civil. Atualmente, sou professora com dedicação exclusiva na Faculdade Santa Maria, lecionando disciplinas direcionadas ao curso de engenharia civil, de nível profissional. Também atuo na Faculdade Santa Maria como coordenadora de estágio do curso de engenharia civil.

${ }^{4}$ Possui graduação em Engenharia Civil pela Universidade Federal da Paraíba (2011) e mestrado em Engenharia Civil e Ambiental pela Universidade Federal da Paraíba (2016). Atualmente é docente do curso de bacharelado em Engenharia Civil da Faculdade Santa Maria, responsável pelas unidades curriculares de Eletrotécnica, Instalações Elétricas Prediais, Instalações Hidrossanitárias, Estradas e Transporte I e II e Concreto Protendido e Pré-moldado.

${ }^{5}$ Possui graduação em Engenharia Civil pela Universidade Federal de Campina Grande (UFCG/ 2014), Mestrado em Estruturas com ênfase em materiais de construção pelo Programa de PósGraduação em Engenharia Civil (PPGEC/ 2017) da Universidade Federal de Pernambuco. Trabalha como Professora na Faculdade Santa Maria - FSM, é responsável pelas unidades curriculares de estruturas de concreto armado, resistência dos materiais I e estática das construções I e estruturas metálicas e de madeira.

${ }^{6}$ Possui graduação em Ciência e Tecnologia e em Engenharia Civil pela Universidade Federal Rural do Semi-Árido - UFERSA (2011-2016). Especialista em docência do ensino superior (2017-2018) pela Faculdade Santa Maria. Mestrado em Sistemas Agroindustriais com linha de pesquisa em recursos hidricos e saneamento ambiental (2017) Pela Universidade Federal de Campina Grande-UFCG. Docente no curso de Graduação em Engenharia Civil da Faculdade Santa Maria - Cajazeiras - PB. Atua na área de Resíduos Sólidos e Recursos Hidricos, é responsável pelas unidades curriculares de materiais de construção civil II, introdução a engenharia civil e eletrotécnica geral.
} 
RESUMO: Objetivo: Avaliar as condições construtivas e a qualidade de água do Programa Um Milhão de Cisternas na comunidade rural Poços em Cajazeiras-PB. Métodos: O estudo constituiu-se de uma pesquisa bibliográfica e posterior realização de um estudo de caso na comunidade rural de Poços, em Cajazeiras-PB, para realizar o diagnóstico do programa. As coletas de dados foram realizadas com inspeções visuais e técnicas in loco e com utilização de Fissurômetro para classificação das manifestações patológicas, logo depois, foi realizado o checklist na comunidade rural, e posteriormente, realizaram-se os registros fotográficos das cisternas, das manifestações patológicas encontradas. Em seguida, foram coletadas amostras de água nas cisternas para verificar sua potabilidade. Resultados: No trabalhou, obteve-se com o checklist, a identificação de problemas desde a localização das cisternas, passando pela ineficiência no processo de manutenção, e também foi apresentado grande número de manifestações patológicas. E por último, a partir dos parâmetros físico-químicos, as análises de $\mathrm{pH}$, cor aparente, turbidez, amônia, nitrito e cloro apresentaram-se, em sua maioria, dentro do estabelecido pela Portaria no 5/2017. Já a análise de nitrato apresentou-se acima do permitido pela Portaria. Conclusão: Concluiu-se que o programa possui ineficiência nas capacitações, no processo construtivo e um grande aparecimento de manifestações patológicas, no qual é preciso buscar medidas sobre uso e aperfeiçoamento da execução das cisternas que reduzam estes problemas.

Descritores: Água pluvial. Armazenamento. Captação. Processos construtivos. Semiárido.

ABSTRACT: Objective: To evaluate the constructive conditions and the water quality of the Program Um Milhão de Cisternas in the rural community of Poços in Cajazeiras-PB. Methods: The study consisted of a bibliographic research and subsequent case study in the rural community of Poços, in Cajazeiras-PB, to perform the diagnosis of the program. The data collections were performed with visual inspections and in situ techniques and measuring the fissures for classification of pathological manifestations, soon after. the checklist was conducted in a rural community, with subsequent photographic records of tanks and pathological manifestations found. Then, samples of water in the tanks were collected to check its potability. Results: The checklist identified problems since the location of tanks, passing through inefficiencies in the process of maintenance, until a great number of pathological manifestations. From the physical-chemical parameters, the analyses of $\mathrm{pH}$, apparent color, turbidity, chlorine, ammonia and nitrite were, in their majority, within the established by Decree $n$. 5/2017. The analysis of nitrate chowed values above the permitted by the aforementioned Decree. Conclusion: The program has inefficiency in the capabilities, in the constructive process and a great appearance of pathological manifestations, in which measures must be sought to use and improve the implementation of the cisterns, which reduce these problems.

Descriptors: Rainwater. Storage. Acquisition. Constructive processes. Semiarid. 


\section{INTRODUÇÃO}

As cisternas de placa do Programa Um Milhão de Cisternas (P1MC) são um sistema de captação e armazenamento de água de chuva, formadas por um reservatório cilíndrico com capacidade de 16 mil litros de água. Sua estrutura é composta por placas de argamassa e cobertura com formato cônico. É uma tecnologia simples, de baixo custo, fácil construção e que é amplamente adotada em todo mundo. Mesmo com índices pluviométricos baixos, característicos da região Semiárida, consegue armazenar água suficiente para consumo humano durante 0 período de escassez.

O programa surgiu em conformidade de dois fatores: o primeiro seria a má distribuição de água - o país concentra em torno de $12 \%$ da água doce do planeta, mas a região Norte detém $80 \%$ desta quantidade de água e apenas $5 \%$ da população nacional, e enquanto nas regiões próximas do Oceano Atlântico, como a região Nordeste, há apenas $3 \%$ da água e $45 \%$ da população brasileira (ANA, 2018). O segundo fator é a escassez hídrica, que gera secas ou estiagens no Brasil e que é caracterizada por condições climáticas desfavoráveis, como chuvas irregulares e mananciais não perenes. Segundo o relatório da Agência Nacional das Águas (2017), entre os anos de 2013 e 2016, 48 milhões de pessoas foram atingidas por secas ou estiagens no país.

Devido à região Semiárida estar interligada diretamente com as secas, que são ocasionadas pela escassez ou ausência de chuvas, buscaram-se medidas para proporcionar o acesso à água potável para população. Assim, foi desenvolvido, pela a Articulação do Semiárido Brasileiro (ASA), o Programa de Formação e Mobilização Social para a Convivência com o Semiárido ou Um Milhão de Cisternas (P1MC).

Este programa é uma forma de proporcionar o acesso à água de qualidade $\mathrm{e}$ em quantidade suficiente para consumo humano na região Semiárida, que iniciou as atividades no ano 2003, que garante à população de regiões rurais o direito à água potável para o consumo, através da implantação de cisternas de placa, e que é 
formado por três etapas principais: a mobilização social, capacitações e construção da cisterna (ASA, 2018).

Diante disto, o trabalho buscou realizar um diagnóstico do Programa Um Milhão de Cisternas. Tem como finalidade apresentar uma caracterização do programa, onde serão abordados, os materiais e processos de construção, o aparecimento de manifestações patológicas e a qualidade da água. E ainda tem uma significativa importância, pois está contribuindo para termos um panorama do programa na comunidade e também colaborando com os profissionais da área de construção civil, para o desenvolvimento de melhor qualidade de cisternas futuras e das já implantadas.

\section{METODOLOGIA}

De maneira geral, o trabalho constituiu-se mediante a realização de uma pesquisa bibliográfica, em trabalhos desenvolvidos com temáticas semelhantes. Posteriormente, houve a realização de um estudo de caso para realizar um diagnóstico do Programa um Milhão de Cisternas (P1MC) na Comunidade Rural localizada na cidade de Cajazeiras-PB.

O estudo utilizado para diagnosticar o Programa um Milhão de Cisternas (P1MC), aconteceu na Comunidade Rural, localizada a $8 \mathrm{~km}$ da zona urbana do Município de Cajazeiras-PB, na região semiárida Paraibana, que tem um total de 153 residências. A vegetação característica é a caatinga, do tipo xerofítico, com espécie de plantas de médio e pequeno porte, como cactáceas e arbustos.

A Comunidade Rural Poços é composta de 153 residências e as cisternas de placa estão presentes em 105 das residências, o que corresponde a $68,62 \%$ do total de casas na comunidade. $O$ processo de coleta de dados foi realizado em 31 cisternas e corresponde aproximadamente a $30 \%$ das cisternas.

Procedeu-se à realização das visitas in loco para analisar o local, efetivandose análises visuais e técnicas na área externa das cisternas. O processo constituiuse inicialmente com identificação visual da manifestação patológica, com auxílio do 
Fissurômetro trident acrílico $85 \times 45$ mm, no qual o instrumento realizou as medições de abertura dimensional das manifestações patológicas de forma rápida e econômica.

Posteriormente, foram realizados os checklists de pesquisa, desenvolvidos utilizando o software Excel da versão 2010, tendo como pontos principais o local da cisterna, a manutenção e os problemas patológicos nas cisternas. O processo de aplicação consistiu em verificar visualmente os pontos abordados, em que as suas respostas foram transcritas para o checklist.

Em seguida, foram realizadas as análises físico-químicas das águas nas cisternas na comunidade Poços. Os parâmetros de qualidade de água analisados foram: os parâmetros físicos de turbidez e cor, os parâmetros químicos que foram: o $\mathrm{pH}$, Amônia, Nitrato e Nitrito. As análises foram realizadas no Laboratório de Saneamento do curso de Engenharia civil, na Faculdade Santa Maria. Tais análises foram provenientes de 10 cisternas, que estão contidas na amostra analisada no trabalho, em que todas as cisternas são utilizadas para consumo humano, as quais são abastecidas com água da chuva.

Os procedimentos realizados para a limpeza e esterilização dos recipientes para os ensaios físico-químicos estão descritos de acordo com o Guia Nacional de Coleta e Preparação de Amostras (2011): foram deixados os frascos e tampas de molho em solução de detergente alcalino $0,1 \%$ por tempo suficiente para facilitar a remoção dos resíduos da amostra e possíveis etiquetas; esfregados os frascos com esponja de aço, e detergente neutro a parte externa dos frascos; enxaguados com água corrente para retirada do detergente; realizados os enxágues finais dos frascos com água destilada ou deionizada e por último, foram tampados e armazenados em local apropriado (livre de poeira).

Os procedimentos realizados para a coleta das amostras de água nas cisternas estiveram de acordo com o Manual de Coleta e Envio de Amostras de Vigilância Ambiental Manual (2014).

Para determinação do potencial Hidrogeniônico $(\mathrm{pH})$ das amostras, utilizou-se o pHmetro, que é um aparelho desenvolvido para determinar o valor de $\mathrm{pH}$ em soluções e tendo um microprocessador com memória para 50 registros para uso em laboratório. O processo consistiu em adicionar uma quantidade suficiente da 
amostra em recipiente, de modo que o eletrodo do aparelho ficasse submerso, e assim obtendo as leituras dos Potenciais Hidrogeniônicos das amostras.

Para a determinação do parâmetro físico cor, utilizou-se o Medidor de Cor GRB, um equipamento especial para medir a cor da água, e que opera pelo sistema de leitura em RGB entre 400 e 700.

Para análise da turbidez, utilizou-se o Tubidímetro, instrumento indicado para medir a concentração de partículas sólidas suspensas na amostra, segundo o princípio nefelométrico.

Para determinação dos parâmetros de cloro DPD, amônia, nitrato e nitrito, foi aplicado o Fotocolorímetro AT100P. Para as análises, foram medidas as quantidades necessárias das amostras e, em paralelo, foram feitas as provas em branco, medido $5 \mathrm{ml}$ de água deionizadas Em seguida, adicionaram-se os reagentes 1 e agitados, os reagentes 2 e agitados e os reagentes 3 e agitados, aguardando posteriormente o tempo necessário para realizar as leituras. Em seguida, o equipamento foi zerado com a prova em branco e realizaram-se as leituras das amostras.

\section{RESULTADOS E DISCUSSÕES}

O primeiro ponto abordado no checklist constituiu-se ao local onde estão inseridas as cisternas. De acordo com a Central das Associações dos Assentamentos do Alto Sertão Paraibano (CAAASP, 2015), o local da cisterna segue alguns pontos que devem ser cumpridos, antes do desenvolvimento da construção.

No gráfico 01 , identificou-se que $84 \%$ das cisternas estão próximas de fossas, lixos, currais ou de raízes de árvores e não atendendo o mínimo de $15 \mathrm{~m}$ de distância relatado pela a Central das Associações dos Assentamentos do Alto Sertão Paraibano (CAAASP, 2015). 
Gráfico 01 - Percentuais de Cisternas em Locais Inadequado.

\section{A CISTERNA ESTÁ A 15 M DE DISTÂNCIA DE FOSSAS, LIXO, CURRAIS E RAÍZES DE ÁRVORES?}

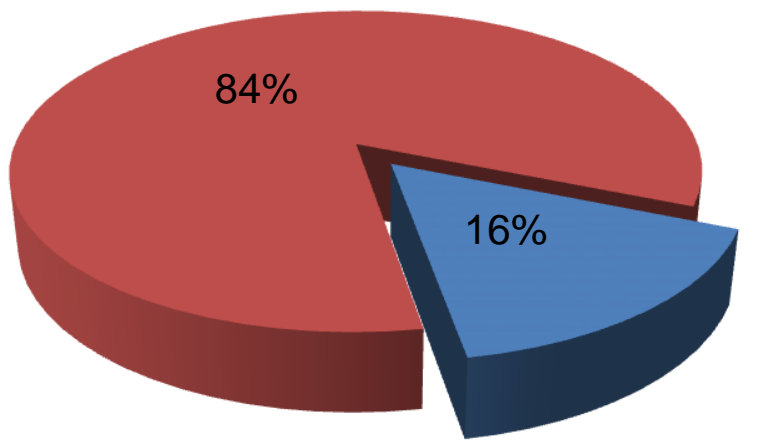

Fonte: (Acervo da autora, 2019).

O Gráfico 02 apresenta que $89 \%$ das cisternas da comunidade estão próximas das cozinhas das residências, atendendo ao que é preconizado pela CAAASP, 2015.

Gráfico 02 - Percentuais de Cisternas Próximas das Residências.

\section{A CISTERNA ESTÁ PRÓXIMA DA COZINHA DA RESIDÊNCIA?}

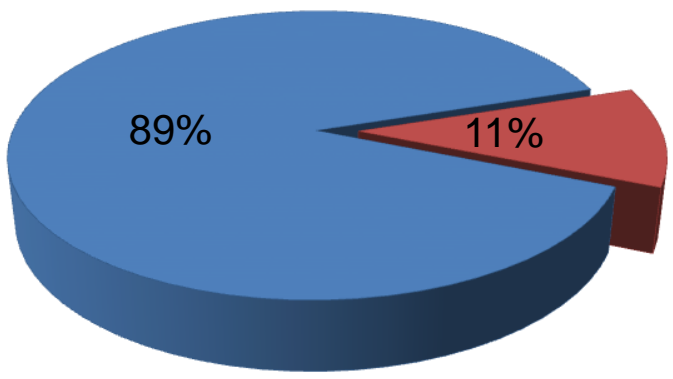

$\square$ SIM

Fonte: (Acervo da autora, 2019).

Já no Gráfico 03, as cisternas da comunidade estão tão próximas das residências, que 77\% não atendem a distâncias mínimas de 1 a 2 metros estabelecidos pela Central das Associações dos Assentamentos do Alto Sertão Paraibano (CAAASP, 2015). 
Gráfico 03 - Percentuais de Distanciamentos entre as Cisternas e a Residências.

\section{A CISTERNA ESTÁ DE 1 A 2 METROS DE DISTÂNCIA DA CASA?}

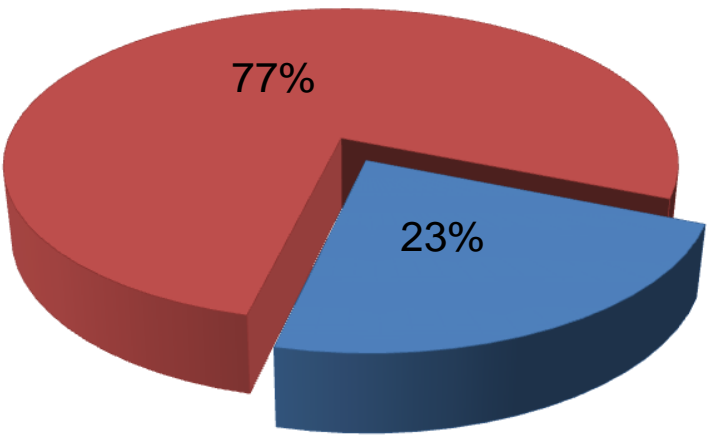

$\square$ SIM

$\square \mathrm{NÃO}$

Fonte: (Acervo da autora, 2019).

A Central das Associações dos Assentamentos do Alto Sertão Paraibano (CAAASP, 2015) descreve que as cisternas devem estar pelo menos a 50 metros de distância dos esgotos, pois, assim como as fossas, currais, lixos e raízes das árvores, os esgotos também propiciam a contaminação das águas das cisternas. $\mathrm{O}$ Gráfico 4 apresenta $74 \%$ das cisternas a menos de 50 metros de distância dos esgotos, de modo relatado RUSKIN(1988), afirmando que vários microrganismos podem estar presentes na água, não só coliformes totais e fecais, mas também várias outras bactérias, como Pseudomonas aeruginosa. 
Gráfico 04 - Percentuais de Cisternas em Locais Contaminados com Esgoto.

\section{A CISTERNA ESTÁ LONGE DO ESGOTO, PELO MENOS 50 METROS?}

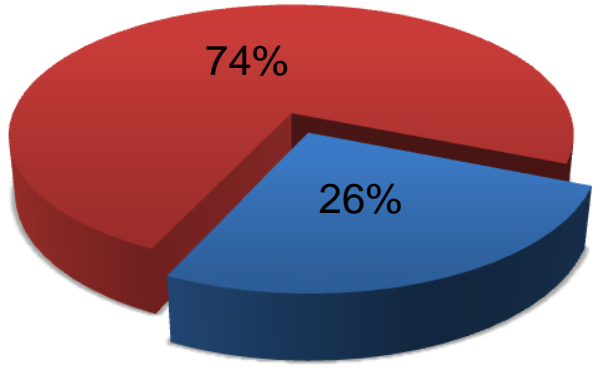

Fonte: (Acervo da autora, 2019).

O Gráfico 5 mostra que os telhados das residências estão em altura superior aos telhados das cisternas, permitindo, assim, que as águas coletadas desçam de todos os lados do sistema de captação por gravidade, fazendo com que o mesmo não necessite de bombas para levar a água até o ponto de consumo.

Gráfico 05 - O Valor Percentual Mediante que deu 100\%.

\section{A CISTERNA ESTÁ ABAIXO DO NÍVEL DO TELHADO?}

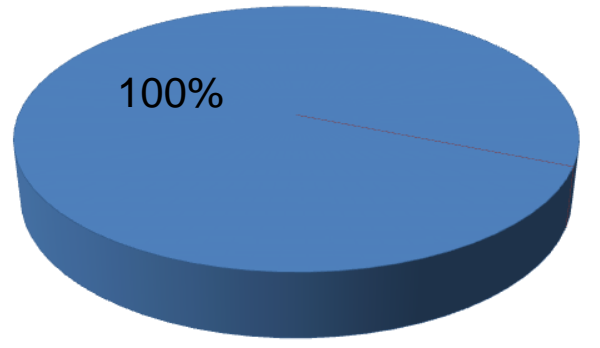

Fonte: (Acervo da autora, 2019).

No Gráfico 6, todas as residências não apresentam telhas de amianto, material que se desintegra facilmente ao sofrer impactos, como envelhecimento, vibrações e águas das chuvas nos telhados, de modo que torna mais provável a liberação da fibra no meio ambiente. 
Gráfico 06 - O Valor Percentual de 100\%.

\section{A CISTERNA ESTÁ IMPLANTADA EM CASA COM TELHA DE AMIANTO?}

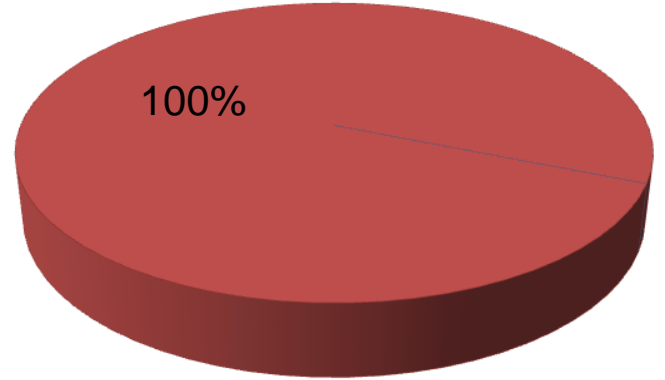

Fonte: (Acervo da autora, 2019).

O segundo ponto abordado no checklist corresponde à segunda fase metodológica do programa, na qual a população, para ser beneficiada com cisterna, precisa passar por uma capacitação, onde são abordados as precauções e responsabilidades com água reservada e os principais cuidados internos e externos que se deve ter nas cisternas, para garantir a eficiência e durabilidade.

O gráfico 7 demonstra que $71 \%$ das cisternas não possuem pinturas em cal, e os $29 \%$ correspondem às pinturas com cal. Segundo o Boletim de Boas Práticas (2015), dentro dos processos de manutenção repassados para população durante o curso, estão os relacionados aos que se devem pintar as cisternas com cal todos os anos tanto na parte interna e como parte externa. 
Gráfico 07 - Percentuais de Cisternas Pintadas com Cal.

\section{A CISTERNA ESTÁ PINTADA COM CAL?}

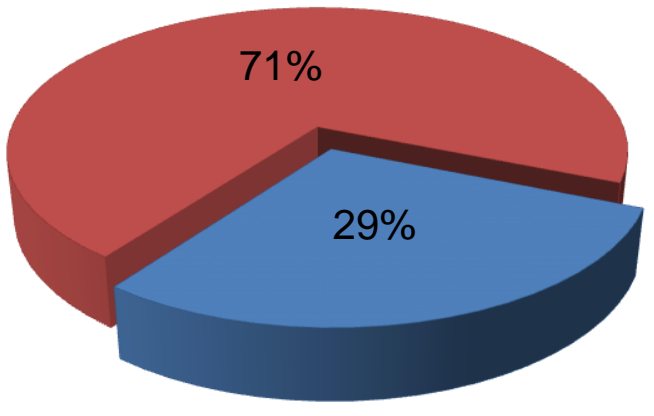

Fonte: (Acervo da autora, 2019).

Já segundo o Gráfico 8, foi identificado, através das inspeções visuais, que maioria da população, $84 \%$, mantém as entradas das cisternas fechadas, impedido a entrada de agentes contaminantes, como insetos, poeiras e entre outros, assim atendendo aos cuidados necessários para evitar a contaminação da água.

Gráfico 08 - Percentuais de cisternas fechadas.

\section{A CISTERNA ESTÁ FECHADA?}

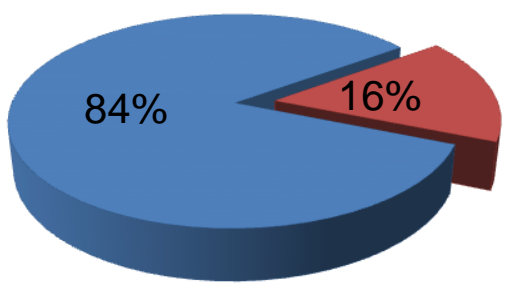

Fonte: (Acervo da autora, 2019).

O sistema de captação de água da chuva não está sendo retirado como relata Gráfico 09 , em que 55\% das pessoas não retiraram o sistema de captação, assim permitindo a entrada dos agentes contaminantes, gerando o desgaste do sistema, por estar exposto constantemente aos intempéries do meio ambiente, como sol e chuva. 
Gráfico 09 - Percentuais Sistema de Captação que está Retirado.

\section{O SISTEMA DE CAPTAÇÃO DE ÁGUA DA CHUVA ESTÁ RETIRADO?}

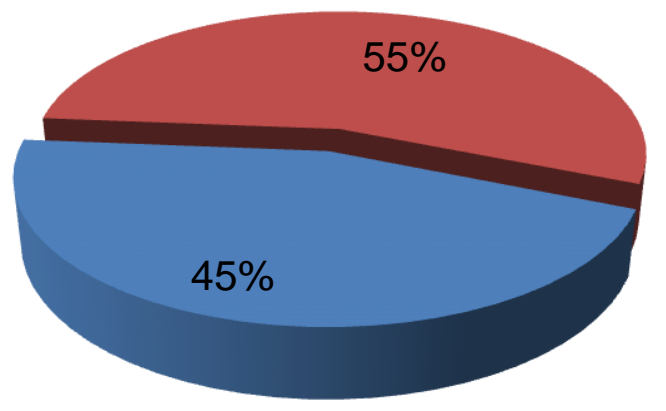

Fonte: (Acervo da autora, 2019).

O terceiro ponto abordado no checklist designou-se a identificar a presença de problemas patológicos, pois, no decorrer do desenvolvimento do programa, as cisternas vêm apresentando ineficiências no seu funcionamento. Os problemas patológicos nas cisternas apresentam-se em $81 \%$ da amostra coletada na comunidade, como demonstra o Gráfico 10 . Tais problemas vão desde a má concepção do sistema de captação à presença de fissuras, trincas, rachaduras e manchas de umidade, desenvolvido por causa da grande variedade de materiais de construção, diferentes processos de execução e não realização de manutenção na cisterna.

Gráfico 10 - Percentuais de Manifestações Patológicos.

\section{A CISTERNA APRESENTA ALGUM MANIFESTAÇÃO PATOLÓGICAS?}

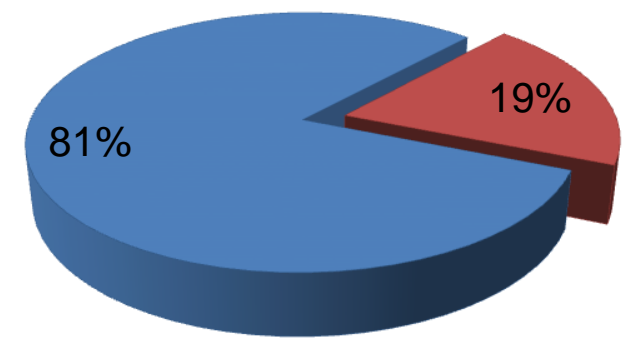

Fonte: (Acervo da autora, 2019). 
O Gráfico 11 mostra os índices de problemas patológicos na comunidade. No ponto relacionado ao mau aproveitamento dos telhados, $23 \%$ da amostra são direcionadas às residências da comunidade compostas por telhados de duas águas, mas que existe apenas um aproveitamento parcial dos telhados para a captação da água da chuva, como relatado na pesquisa de Silva, Barbosa e Antunes (2012), que se refere a problemas patológicos de concepção do sistema de captação, onde se tem subaproveitamento das áreas dos telhados.

As fissuras estão presentes em $35 \%$ das amostras, as trincas estão presentes em $23 \%$ das amostras, rachaduras estão presentes em $12 \%$ das amostras e as manchas de umidade estão presentes em 7\% das amostras das cisternas. Como relata VIEIRA et al., 2017, tais manifestações estão acontecendo devido aos possíveis processos ineficientes de impermeabilização.

Gráfico 11 - Percentuais de tipos de Manifestações Patológicos.

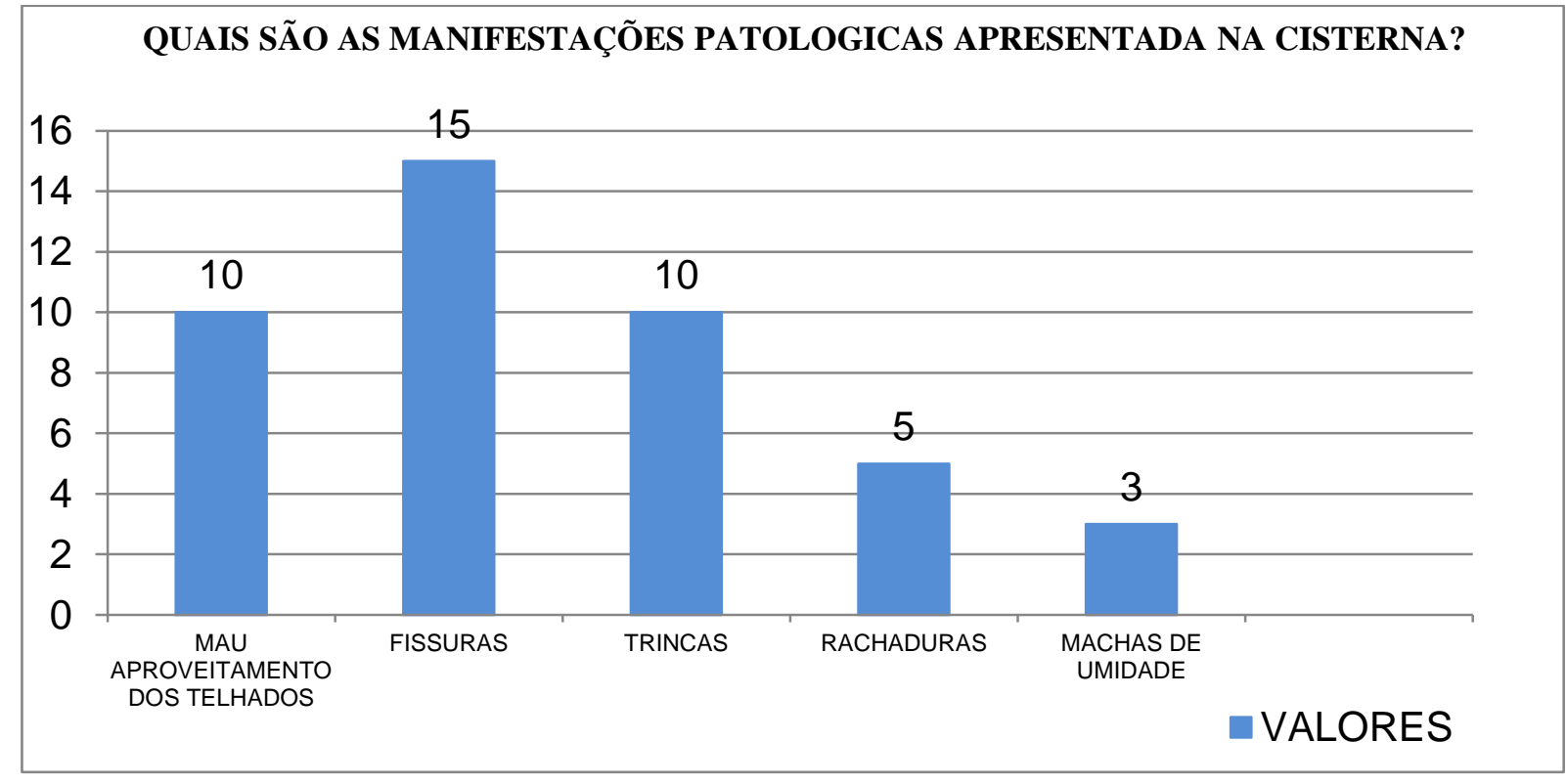

Fonte: (Acervo da autora, 2019).

Diante do que foi analisado no Gráfico 12, nota-se uma variação de pH entre 8,11 a 9,05 nas amostras, sendo considerado básico, faixa considerada ideal para nosso organismo, por torná-lo mais imune às doenças. Os resultados apresentados não tiveram nenhum valor acima do que é previsto na Portaria da Consolidação no 
5/2017, no Anexo XX, que são variações na faixa de 6,0 a 9,5 no sistema de distribuição.

Gráfico 12 - Variação do Potencial Hidrogênionico das Cisternas.

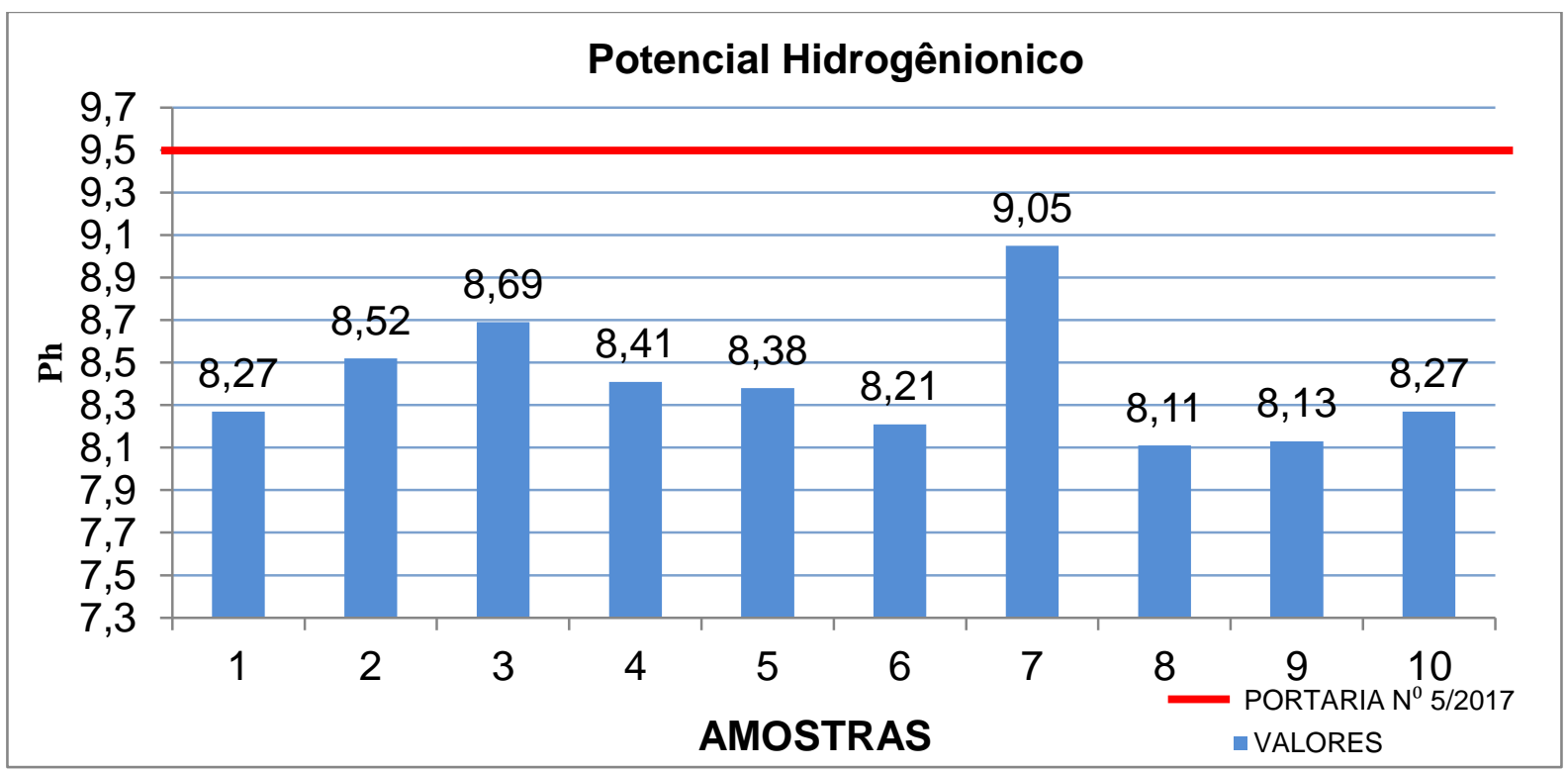

Fonte: (Acervo da autora, 2019).

$\mathrm{Na}$ análise do parâmetro de Cor Aparente (Gráfico 13), identificou-se que 90\% das amostras estão dentro dos parâmetros fixados pela Portaria $n^{0}$ 5/2017, que estabelece o valor máximo para a Cor de 15 Uh. Idetificando, assim, na maior parte das amostras, a inesistência de substâncias dissovidas na água. 
Gráfico 13 - Variação da Cor Aparente.

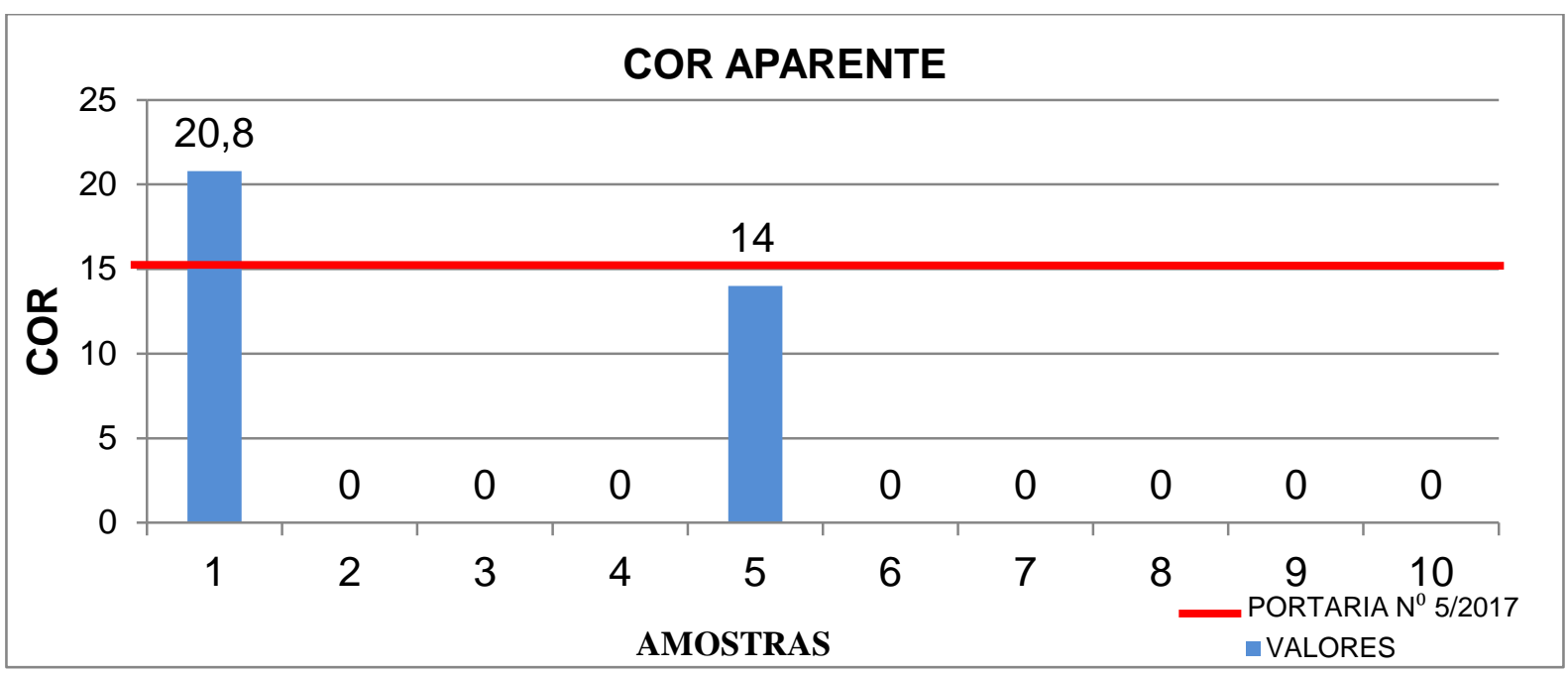

Fonte: (Acervo da autora, 2019).

O parâmetro de Turbidez (Gráfico 13) mostra que $80 \%$ das amostras estão dentro dos parâmetros fixados pela Portaria ํㅡㄴ 5/2017, que estabelece um valor máximo de 5 NTU e apenas $20 \%$ estão acima da Portaria.

Gráfico 14 - Variação de Turbidez.

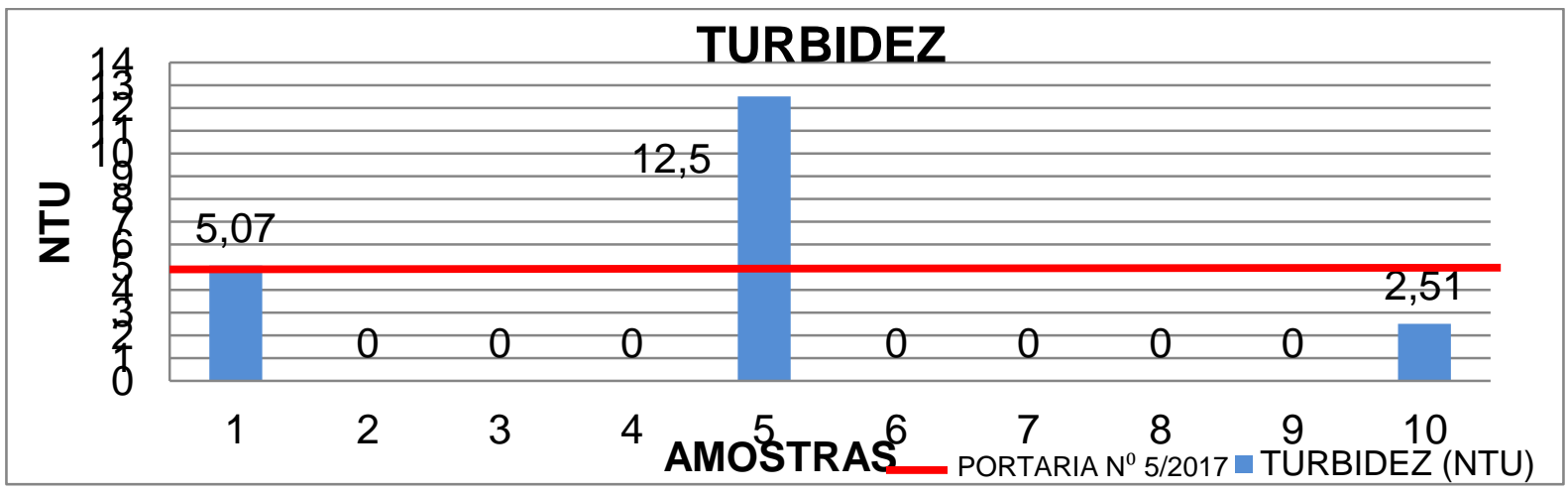

Fonte: (Acervo da autora, 2019).

Conforme pode ser verificado no Gráfico 15 , observa-se que $80 \%$ das amostras apresentaram níveis resultantes de Nitrato acima de $10 \mathrm{mg} / \mathrm{l}$ do valor máximo permitido pela Portaria no 5/2017 e apenas 20\% dentro do permitido pela Portaria. 
O Nitrato é contaminante inorgânico, que ocorre normalmente em zonas rurais e suburbanas, origina-se de quatros fontes principais: utilização dos fertilizantes em plantações, do esterco animal, esgoto e deposição atmosférica, e seu excesso na água pode causar em recém-nascidos a síndrome do bebê azul, e nos adultos, como relatam pesquisas, pode causar doenças cancerígenas (BAIRD; CANN, 2011).

Gráfico 15 - Variação de Nitrato.

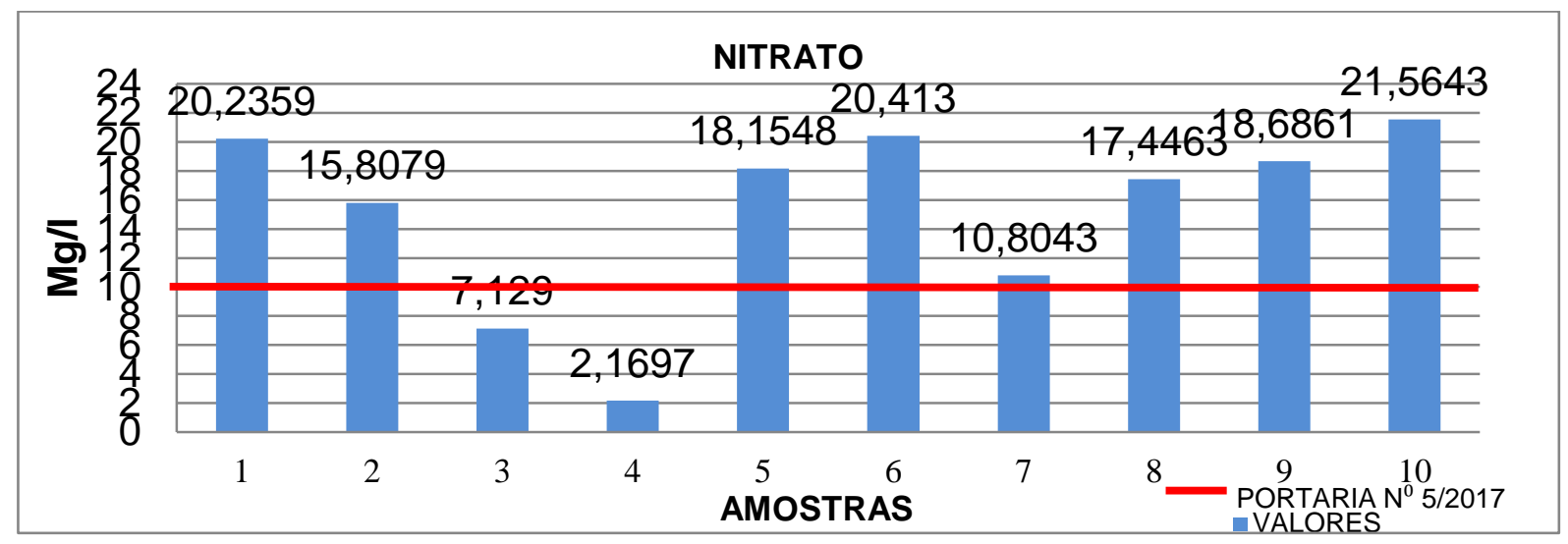

Fonte: (Acervo da autora, 2019).

Mesmo sendo águas captadas por precipitação, podendo apresentar maiores concentrações, o parâmetro de Nitrito (Gráfico 16) apresenta 90\% das amostras dentro do valor máximo estabelecido pela Portaria $\mathrm{n}^{\circ}$ 5/2017, que é de $1 \mathrm{mg} / \mathrm{l}$, assim realizando conversão dos nitritos em nitratos e apenas $10 \%$ não estão dentro do que é estabelecido pela Portaria. 
Gráfico 16 - Variação de Nitrito.

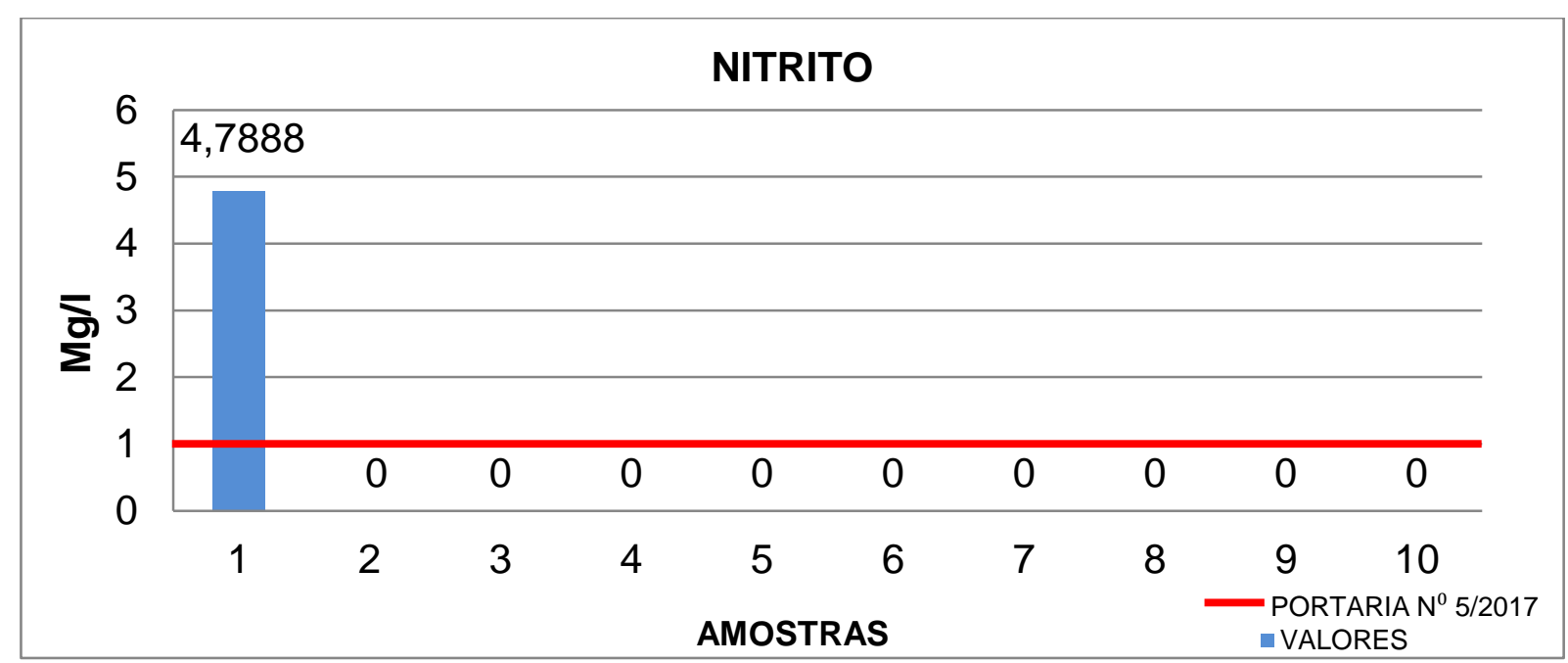

Fonte: (Acervo da autora, 2019).

Amônia e seus derivados, como o nitrato, são utilizados na agricultura como fertilizantes. A amônia pode estar presente nas águas, em baixos níveis, devido ao processo de degeneração biológica da matéria orgânica animal e vegetal (Tratamento de água, 2008). O parâmetro químico de Amônia (Gráfico 17) está dentro do estabelecido pela Portaria ํㅜ 5/2017, em que as águas das cisternas estão em conformidade com o padrão de aceitação para o consumo humano, cujo valor máximo para a Amônia é de $1,5 \mathrm{mg} / \mathrm{l}$. 
Gráfico 17 - Variação de Amônia.

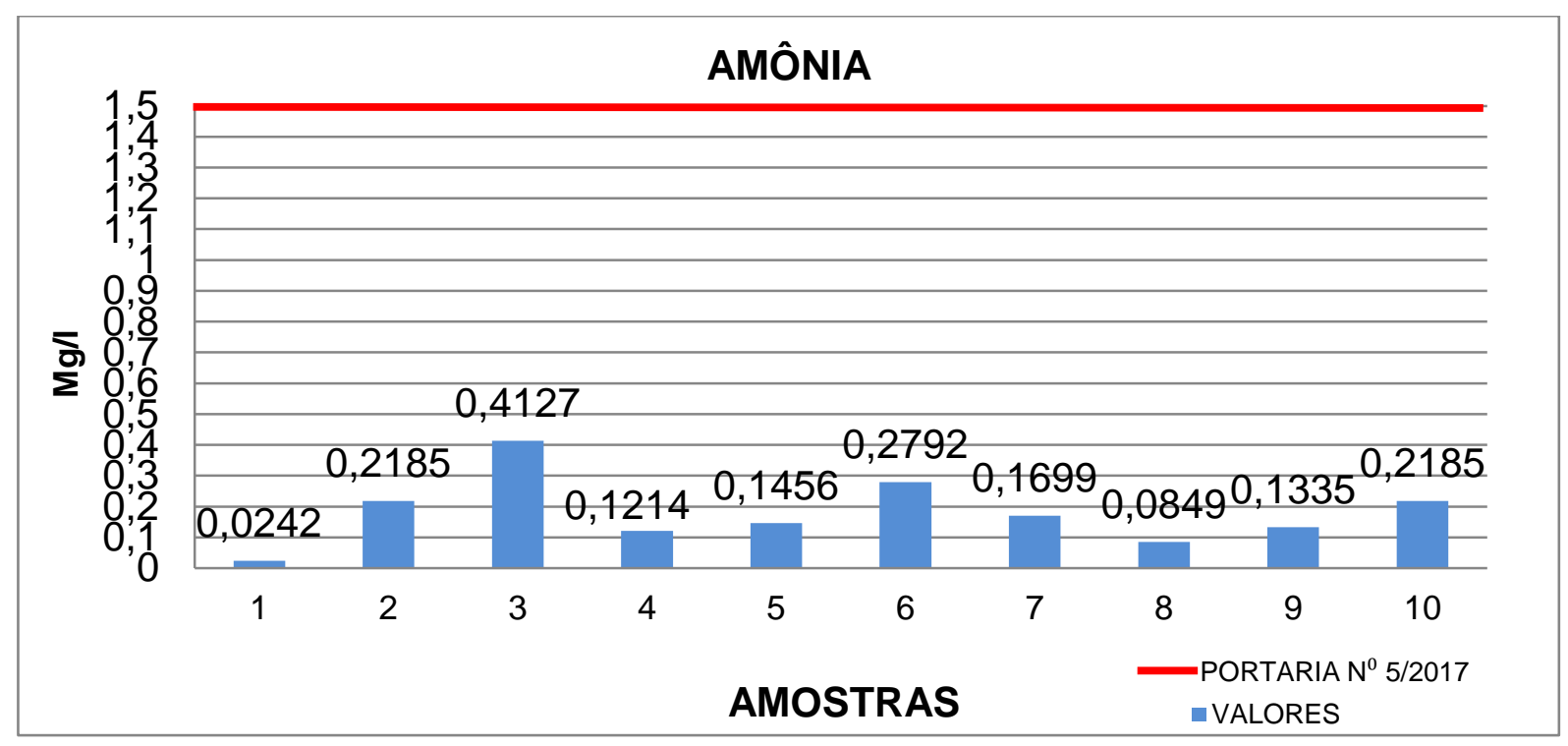

Fonte: (Acervo da autora, 2019).

As amostras de Cloro DPD (Gráfico 18) não apresentaram o teor mínimo de cloro residual livre de $0,2 \mathrm{mg} / \mathrm{l}$ que deve estar presente na água em toda a extensão do sistema de distribuição, para garantir a potabilidade da água. A cloração é considerada um processo de desinfecção aplicada nas água para melhoria da qualidade bacteriológica e segurança sanitária, e a sua não realização propicia a proliferação dos microrganismos patogênicos nas águas (SAAE, 2013). 
Gráfico 18 - Variação de Cloro.

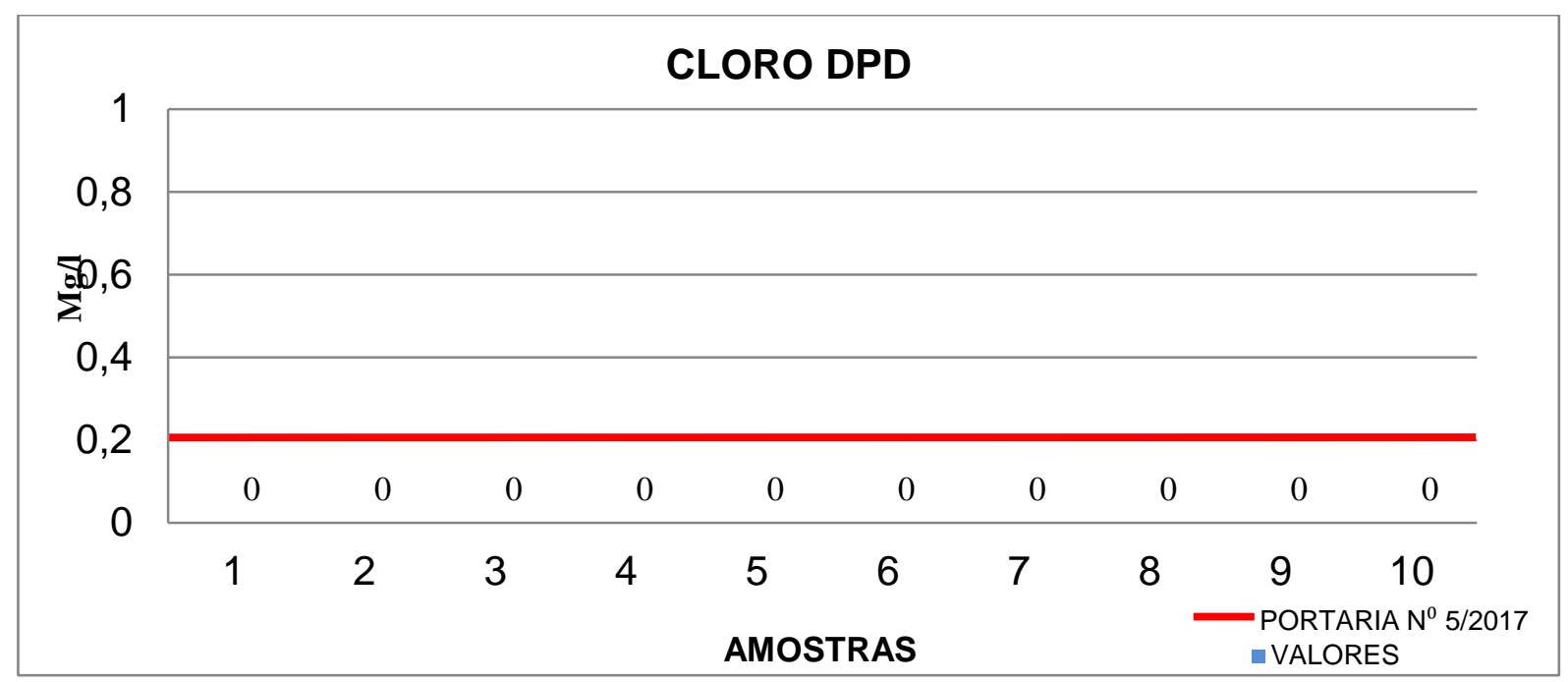

Fonte: (Acervo da autora, 2019).

\section{CONCLUSÃO}

A partir da realização do trabalho, evidenciaram-se alguns padrões que estiveram incoerentes com o padrão de construção, como no processo de escolha do local da cisterna, em que as mesmas, em sua maioria, estão próximas de locais contaminados, e também se identificou que as famílias beneficiadas com as cisternas não sabem lidar adequadamente com a tecnologia implementada, em sua maneira de manutenção e de manejo, pois, na maioria das vezes, não realizam os principais pontos de manutenção, como a pintura com cal e não retiram o sistema de captação, o que é resultado de uma ineficiência no processo de capacitações das famílias e dos profissionais que desenvolvem as cisternas.

Além disso, no trabalho, também houve manifestações patológicas, destacando como principal tipo as fissuras, decorrentes de uma má capacitação no processo de produção, uma mão de obra não tão qualificada, gerando erros construtivos e também a má realização das manutenções.

Os parâmetros físico-químicos analisados atenderam, em sua maioria, os padrões determinados pela Portaria da Consolidação nํ5/2017, Anexo XX. Tanto os 
padrões físicos como os químicos obtiveram apenas alguns pontos das amostras acima do estabelecido pela portaria, devido à má conservação das cisternas. 0 único parâmetro químico que se mostrou acima do permitido foi o relacionado ao nitrato, decorrente da utilização dos fertilizantes na zona rural.

Ao final desta pesquisa, é possível constatar que mesmo o programa tendo como obrigação a participação de um membro da família e dos profissionais que realizam o processo de construção das cisternas nas capacitações, identifica-se uma ineficiência no processo de capacitação. Este tem que ser um dos principais focos do programa para garantir eficiência do sistema, seja através de pesquisa relacionada aos aspectos construtivos e a materiais de construção mais acessíveis para cada região, ou através do aperfeiçoamento sobre a educação no uso e nas manutenções desta tecnologia.

\section{REFERÊNCIAS BIBLIOGRÁFICAS}

AGÊNCIA NACIONAL DAS ÁGUAS (ANA). Água No Mundo. Disponível em: <http://www3.ana.gov.br/portal/ANA/panorama-das-aguas/agua-no-mundo >. Acesso em: 9 de novembro de 2018.

AGÊNCIA NACIONAL DAS ÁGUAS (2017). Relatório Da ANA Apresenta Situação Das Águas Do Brasil No Contexto De Crise Hídrica. Publicado em 4 de dezembro, 2017. Disponível em: < www.ana.gov.br>. Acesso em: 04 de novembro de 2018.

AGÊNCIA NACIONAL DAS ÁGUAS (ANA). Guia Nacional De coleta e Preservação De amostras. Brasília-DF, 2011. Disponível:<www.ana.gov.br>. Acesso em: 29 de janeiro de 2019.

ARTICULAÇÃO NO SEMIÁRIDO BRASILEIRO (ASA). Associação Programa Um Milhão De Cisternas (AP1MC). Disponível em:<http://www.asabrasil.org.br/sobre-nos/ap1mc>. Acesso em: 20 de agosto de 2018.

ARTICULAÇÃO NO SEMIÁRIDO BRASILEIRO (ASA). Historia. Disponível em:< http://www.asabrasil.org.br/sobre-nos/historia\#como-surgimos>. Acesso em: 19 de agosto de 2018.

ARTICULAÇÃO NO SEMIÁRIDO BRASILEIRO (ASA). Mapa De Tecnologias. Disponível em:<http://www.asabrasil.org.br/mapatecnologias/>. Acesso em: 20 de agosto de 2018.

ARTICULAÇÃO NO SEMIÁRIDO BRASILEIRO (ASA). Programa Uma Terra e Duas Águas (P1+2). Disponível em:<http://www.asabrasil.org.br/acoes/p1-2>. Acesso em: 20 de agosto de 2018.

ARTICULAÇÃO NO SEMIÁRIDO BRASILEIRO (ASA). Semiárido - É no semiárido que a vida pulsa. Disponível em:<http://www.asabrasil.org.br/semiarido>. Acesso em: 20 de agosto de 
2018.

ARTICULAÇÃO NO SEMIÁRIDO BRASILEIRO MINAS (ASAMINAS). Asa investe em mão de obra local para construção de cisternas. Disponível em: $<$ http://www.asaminas.org.br/blog/post/asa-investe-em-mao-de-obra-local-para-construcao-decisternas>. Acesso em: 29 de janeiro de 2019.

ASSOCIAÇÃO BRASILEIRA DE NORMAS TÉCNICAS. NBR 15575-2: Edificações Habitacionais - Desempenho. Rio de Janeiro, 2013.

ASSOCIAÇÃO BRASILEIRA DE NORMAS TÉCNICAS. NBR 9575: Impermeabilização Seleção E Projeto. Rio de Janeiro, 2003.

ASSOCIAÇÃO PORTUGUESA DE DISTRIBUIÇÃO E DRENAGEM DE ÁGUAS (APDA). FT-QINITRITOS. Disponível em:<https://www.apda.pt/site/ficheiros_eventos/201302261000ft_qi_14_nitrito.pdf>. Acesso em: 28 de maio de 2019.

BAIRD, C.; CANN, M. Química Ambiental. 4. ed. Porto Alegre: Bookman, 2011.

BELTRÃO, Breno Augusto et al. Projeto cadastro de fontes de abastecimento por água subterrânea, estado de Paraíba: diagnóstico do município de Cajazeiras. Recife, 2005.

BRASIL. Ministério de Desenvolvimento Social. SIG Cisternas. Disponível em:<http://mds.gov.br/assuntos/seguranca-alimentar/acesso-a-agua-1/sig-cisternas>. Acesso em: 20 de agosto de 2018.

BRASIL. Ministério da Saúde. Portaria no 2.914, de 12 de dezembro de 2011. Disponível em: < http://bvsms.saude.gov.br/bvs/saudelegis/gm/2011/prt2914_12_12_2011.html>.

BRASIL. Sistema de Gestão da Informação e do Conhecimento do Semiárido Brasileiro (SIGSAB). Índice De Desenvolvimento Humano Municipal - IDHM. Disponível em:<http://sigsab.insa.gov.br/welcome>. Acesso em: 20 de agosto de 2018.

BRASIL. Sistema de Gestão da Informação e do Conhecimento do Semiárido Brasileiro (SIGSAB). Estabelecimentos agropecuários do semiárido brasileiro. Disponível em:<http://sigsab.insa.gov.br/welcome>. Acesso em: 20 de agosto de 2018.

CENTRO DIOCESANO DE APOIO AO PEQUENO PRODUTOR (CEDAPP). Água da vida, construindo a cisterna de placas. Pesqueira, 2010.

CENTRAL DAS ASSOCIAÇÕES DOS ASSENTAMENTOS DO ALTO SERTÃO PARAIBANO (CAAASP). Boletim de boas práticas. Cajazeiras, Ano 1. N. 01, Abril/2015.

CENTRAL DAS ASSOCIAÇÕES DOS ASSENTAMENTOS DO ALTO SERTÃO PARAIBANO (CAAASP). Processo de construção das cisternas. Cajazeiras, 2015.

COMISSÃO NACIONAL DE ÉTICA EM PESQUISA (CONEP). Resolução CNS no 510/2016 Procedimentos Metodológicos Característicos das Áreas de Ciências Humanas e Sociais. Conselho Nacional de Saúde, 2017.

DECLARAÇÃO DO SEMIÁRIDO. Propostas da articulação no semiárido brasileiro para a convivência com o semiárido e combate à desertificação. Recife, 1999.

DE SOUZA, V. C. M.; RIPPER, T. Patologia, Recuperação E Reforço De Estruturas De Concreto. São Paulo, Editora PINI, 1998.

GOOGLE EARTH. Disponível em: <https://earth.google.com/web/>. Acesso em: 03 de outubro de 2018. 
HELENE, P. R. L. Manual para reparo, reforço e proteção das estruturas de concreto. São Paulo: Editora PINI, 1992.

LABORATÓRIO CENTRAL DO ESTADO DO PARANÁ (LACEN). Manual de coleta e envio de amostras de vigilância ambiental. Curitiba- PR, 2014.

MODELO da tecnologia social de acesso à água № 01 . Cisternas de placas de 16 mil litros. 2015. Disponível em:

http://www.mds.gov.br/webarquivos/arquivo/seguranca_alimentar/cisternas_marcolegal/tecnologi as_sociais/Cisterna\%20de\%20Placa\%20de\%2016\%20mil\%20litros01/IO_SESAN_n1_0707201 5_ANEXO.pdf>.

MIZAEL, S.S. Análise do uso de sistemas de captação e armazenamento de água da chuva em comunidade do semiárido rural, por métodos simplificados. Juazeiro do Norte, 2018.

TRATAMENTO de água. Parâmetros analíticos. 2008. Disponível em:< https://www.tratamentodeagua.com.br/artigo/parametros-analiticos/>. Acesso em: 28 de maio de 2019.

SERVIÇO AUTÔNOMO DE ÁGUA E ESGOTO DE SÃO MATEUS (SAAE). Tratamento de água. Disponível em:<http://www.saaesma.com.br/tratamento>. Acesso em: 29 de maio de 2019.

SILVA, C.V. Qualidade da água de chuva para consumo humano armazenada em cisternas de placa - estudo de caso: Araçuaí, MG. 2006. 136 f. Dissertação (Mestrado em Saneamento, Meio Ambiente e Recursos Hídricos) - Escola de Engenharia, Universidade Federal de Minas Gerais. Belo Horizonte, 2006.

SILVA, M.F; BARBOSA, N; ANTUNES, L. Patologias em sistemas de captação de água de chuva por meio de cisternas no semiárido paraibano. In: SIMPÓSIO BRASILEIRO DE CAPTAÇÃO E MANEJO DE ÁGUA DE CHUVA, 8., 2012, Campina Grande. Paraíba, 2012.

SILVA, J.; SILVA, B. Modelo conceitual do programa cisternas rurais: uma análise em Sergipe. In: SIMPÓSIO BRASILEIRO DE CAPTAÇÃO E MANEJO DE ÁGUA DE CHUVA, 7., 2009, Caruaru. Pernambuco, 2009.

VIEIRA, G. et al. Análise das manifestações patológicas em cisternas de placas no semiárido de Monteiro-PB. In: CONGRESSO INTERNACIONAL DA DIVERSIDADE DO SEMIÁRIDO, 2017, Campina Grande. Paraíba, 2017. 